\title{
Qualidade da Carne de Cordeiros Criados em Creep Feeding com Silagem de Grãos Úmidos de Milho ${ }^{1}$
}

\author{
Gercílio Alves de Almeida Júnior², Ciniro Costa ${ }^{3}$, Alda Lúcia Gomes Monteiro4, Cledson \\ Augusto Garcia ${ }^{2}$, Danísio Prado Munari ${ }^{5}$, Marcela Abbado Neres ${ }^{6}$
}

RESUMO - Objetivou-se, com este trabalho, estudar níveis de substituição (0; 50 e 100\%) do milho grão seco moído pela silagem de grãos úmidos de milho (SGUM) na ração de cordeiros alimentados em creep feeding. Vinte e quatro cordeiros Suffolk foram avaliados quanto às características quantitativas e qualitativas do músculo longissimus dorsi. Os animais foram abatidos ao atingirem 28 kg PV e suas carcaças resfriadas foram seccionadas em sete regiões anatômicas. Sobre a superfície do longissimus dorsi, no corte denominado lombo, foram tomadas as medidas: largura e profundidade máximas; mínima e máxima espessuras de gordura de cobertura e área de olho de lombo. Nos lombos, determinaram-se as proporções dos tecidos muscular, adiposo e ósseo, a composição química e a força de cisalhamento. Os resultados revelaram que não houve efeito dos tratamentos para a força de cisalhamento e nem para as medidas tomadas no longissimus dorsi, exceto para a área de olho de lombo, segundo regressão quadrática, com maiores valores para os tratamentos com SGUM. As análises de composição química do longissimus dorsi revelaram que os tratamentos influenciaram o teor de gordura no músculo, que aumentou linearmente de acordo com a inclusão de SGUM na ração. Não foi verificado efeito dos tratamentos sobre a composição tecidual dos lombos. Concluiu-se que é possível recomendar a substituição do milho grão pela silagem de grãos úmidos de milho para a dieta de cordeiros terminados em creep feeding, conservando a boa qualidade da carne.

Palavras-chave: lombo, maciez, ovinos, qualidade de carne

\section{Meat Quality of Lambs Fed With High Moisture Corn Silage in Creep Feeding}

\begin{abstract}
The experiment was carried to study three three levels (0, 50 e 100\%) of high moisture corn silage replacing dry corn grain in rations of lambs fed in creep feeding. Twenty four Suffolk lambs were evaluated to qualitative and quantitative loin (longissimus dorsi) characteristics. Lambs were weighed until to reach pre-fixed slaughter weight, $28 \mathrm{~kg}$ LW. Cold carcasses were cut in seven anatomical regions. Four measures were taken on longissimus dorsi surface: maximum width; minimal depth; minimal fat depth and maximum fat depth and loin eye area. Loins were dessecated to determine muscle, fat and bone proportions, chemical composition and shear force. Results showed that replacing levels did not affect shear force and loin measures, except for loin eye area, according to quadratic regression with higher values observed in rations with high moisture corn silage. Chemical composition analysis showed that replacing levels just influenced loin fat content, that increased linearly according to silage adding. There was no effect on muscle, bone and fat proportions, considering corn replacing levels. It was concluded that is possible replace dry corn by high moisture corn silage in creep feeding rations to finish lambs, keeping good quality meat.
\end{abstract}

Key Words: loin, meat quality, sheep, tenderness

\section{Introdução}

O Brasil dispõe de um rebanho ovino estimado em 14,8 milhões de cabeças, sendo que $90 \%$ desses animais se encontram nas regiões Nordeste e Sul e apenas 3\% na região Sudeste (IBGE, 2001). Porém, apesar da pequena representatividade na produção nacional, esta região, em particular o Estado de São Paulo, se destaca como mercado potencial para a carne ovina de qualidade (Neto, 1997; Cunha et al., 2000).

O consumo de carne ovina no país ainda é muito pequeno, tanto em valores absolutos quanto em valores comparativos às demais carnes. De acordo com Silva Sobrinho (2001), o consumo per capita de carne ovina no Brasil não ultrapassa os $30 \mathrm{~g} /$ habitante/ano, sendo mais elevado no Estado do Rio Grande do Sul. Esse

\footnotetext{
${ }^{1}$ Projeto financiado pela Universidade de Marília e UNESP, parte da Dissertação do primeiro autor para obtenção do título de Mestre em Zootecnia na FMVZ-UNESP.

2 Professores do Depto. de Zootecnia da Faculdade de Ciências Agrárias da Universidade de Marília, CEP: 17525-902, Marília, SP. E.mail: gercilio@unimar.br; cgarcia-ca@unimar.br

${ }^{3}$ Professor do Departamento de Melhoramento e Nutrição Animal da FMVZ-UNESP, Botucatu, SP. E.mail: ciniro@fca.unesp.br

${ }^{4}$ Professora Adjunta do Departamento de Zootecnia da Universidade Federal do Paraná, Curitiba, PR. E.mail: alda.Igm@ufpr.br

5 Professor Assistente Doutor do Departamento de Ciências Exatas da FCAV-UNESP, Jaboticabal, SP. E.mail: danisio@fcav.unesp.br

${ }^{6}$ Professora do CCA, UNIOESTE, Mal. Cândido Rondon, PR. E.mail: abbado@unioeste.br
} 
mesmo autor relata o consumo médio de $20 \mathrm{~kg} /$ habitante/ano na Austrália e Nova Zelândia. Simplício (2001) afirmou que o consumo da carne ovina, bem como da caprina, cresceu muito nos últimos anos, porém, segundo estimativas, as duas juntas ainda não superam a quantia de $1,5 \mathrm{~kg} /$ habitante/ano, quantidade muito pequena em comparação ao consumo per capita no Brasil das carnes de bovinos, suínos e aves (42, 12 e $28 \mathrm{~kg}$, respectivamente).

Fatores como hábito alimentar e poder aquisitivo exercem grande influência sobre o consumo da carne ovina. No entanto, alguns autores relatam que um dos fatores mais preponderantes para a expansão e consolidação do mercado dessa carne no Brasil é a qualidade das carcaças produzidas, sendo fundamental a padronização das mesmas em função de tamanho, percentual de músculos, cobertura de gordura subcutânea e teor de gordura adequado ao mercado (Bueno et al., 2000; Siqueira et al. 2001a).

O mercado nacional é abastecido, principalmente, com carne ovina proveniente de animais velhos com baixa qualidade de carcaça, o que exerce influência inibitória sobre o seu consumo, gerando tabus alimentares entre os consumidores. Vale ressaltar que a qualidade, no tocante à carne ovina, está relacionada a diversos fatores relativos ao animal, ao meio, à nutrição, ao manejo antes do abate e às condições de processamento e conservação das carcaças após o abate (Silva \& Pires, 2000; Garcia et al., 2000; Sañudo, 2002).

No entanto, de acordo com Cunha et al. (2000), o consumo de carne ovina com qualidade superior proveniente do abate de animais jovens tem aumentado nos últimos anos. Contudo, o mercado para a carne com qualidade superior ainda tem sido abastecido principalmente pelas importações oriundas do Uruguai, Argentina e Nova Zelândia (Simplício, 2001).

Descrevendo características inerentes aos hábitos de consumo de carne ovina em diferentes países europeus, Sañudo (2002) destacou que altas eficiências técnica e econômica na ovinocultura são necessárias para que a mesma se consolide em mercados mais exigentes onde o consumo é maior, porém já estabilizado, e os custos de produção são elevados e as margens de lucro, menores. Esse autor destaca que, neste contexto, a produção de carne de qualidade deve ser prioridade. No cenário nacional, este fato deve ser considerado para que a ovinocultura brasileira possa consolidar não apenas o seu espaço no mercado interno, mas também em um mercado externo marcado por intensa competitividade.
Na busca por melhores resultados zootécnicos e econômicos, raças precoces especializadas para a produção de carne têm sido introduzidas no rebanho nacional. O uso crescente de diversas estratégias de suplementação alimentar tem sido adotado em oposição aos sistemas tradicionais de terminação a pasto, com o objetivo de diminuir a idade ao abate e melhorar a qualidade da carcaça (Macedo et al., 2000; Siqueira \& Fernandes, 2000).

A utilização de comedouros seletivos (creep feeding) para alimentar os cordeiros junto às matrizes confere maiores possibilidades de ganho de peso e, conseqüentemente, menor idade ao abate, uma vez que os animais não precisam ser desmamados durante o período de suplementação. Com menor idade ao abate, obtêm-se carcaças com qualidade superior.

A gordura pode alterar algumas características da carne, principalmente em função de sua quantidade total e do local de deposição na carcaça. Nesse sentido, a adoção da silagem de grãos úmidos de milho na alimentação de ovinos pode influenciar as características das carcaças dos mesmos, uma vez que, por ser um alimento com melhor digestão ruminal do amido, em relação ao milho seco moído, pode alterar os locais de deposição de tecido adiposo, com menor deposição de gordura visceral e maior de gordura inter e intramuscular e/ou subcutânea. Diversos autores afirmaram que a utilização predominante de fontes de amido de baixa degradação ruminal (como o milho seco moído) favoreceu a deposição de gordura visceral em bovinos de corte e ovinos (Owens et al., 1986; Taniguchi et al., 1995; Luchiari Filho \& Moura, 1998).

Este trabalho foi conduzido com o objetivo de avaliar o efeito da substituição de grãos secos de milho (moídos) pela silagem de grãos úmidos de milho, como componente energético das rações para cordeiros criados e terminados em creep feeding, sobre as características quantitativas e qualitativas do músculo longissimus dorsi.

\section{Material e Métodos}

Foram avaliados níveis de substituição (0; 50 e $100 \%$ ) de grãos secos de milho (GSM) pela silagem de grãos úmidos de milho (SGUM) para cordeiros alimentados ad libitum, duas vezes ao dia, em creep feeding. Foram usadas três rações balanceadas para 21\% de proteína bruta na matéria seca e 2,7 Mcal EM/kg MS, compostas com feno de alfafa moído, 
farelo de soja, milho moído e/ou silagem de grãos úmidos como componentes energéticos, mais núcleo mineral-vitamínico comercial e cloreto de sódio.

Após o nascimento, 24 cordeiros inteiros Suffolk foram pesados, numerados com tinta e colocados junto com as matrizes em piquetes com grama-estrela branca [Cynodon plectostachyus (K. Schum.) Pilger]. Os animais foram divididos em três tratamentos, totalizando oito machos em cada um. Os cordeiros oriundos de partos múltiplos foram distribuídos uniformemente entre os tratamentos, uma vez que normalmente apresentam menores pesos ao nascimento e podem ter velocidade menor de crescimento, já que o leite materno tem que ser dividido com outro cordeiro.

Para cada tratamento, foram usados dois piquetes, em que as matrizes e seus respectivos cordeiros foram manejados em pastejo alternado durante o experimento. As matrizes receberam, além da forragem disponível nos piquetes, suplementação de ração concentrada (16\% PB) a $8 \%$ do peso vivo por ovelha por dia.

Aos 14 e 44 dias de idade, os cordeiros foram vacinados contra clostridioses (Polivalente Sintoxan $\left.{ }^{\circledR}\right)$. O monitoramento de infecções parasitárias foi feito quinzenalmente por coleta de fezes direto da ampola retal dos cordeiros e ovelhas, para a contagem do número de ovos por grama de fezes (OPG), segundo metodologia de Matos \& Matos (1998). As ovelhas foram desverminadas duas vezes durante o experimento - na primeira, receberam, em injeção subcutânea, disofenol 2,6 diiodo 4 nitrofenol (Rumivac® ${ }^{\circledR}$ 30) e na segunda, aplicação subcutânea de moxidectina $1 \%$ (Cydectin ${ }^{\circledR}$ NF). Nos cordeiros, não foi realizada desverminação, porque nas contagens não foram encontrados números acima de 500 OPG quantidade referencial para tratamento (Garcia, 2002).

Os animais foram pesados a cada 14 dias. À medida que atingiram $28 \mathrm{~kg}$ de peso vivo (peso final), os animais foram apartados das ovelhas e submetidos a jejum de alimentos sólidos por 16 horas, quando foram novamente pesados (peso vivo ao abate) e, em seguida, abatidos.

Após a evisceração, as carcaças foram levadas para câmara de refrigeração, permanecendo penduradas pela articulação tarso-metatarsiana em ganchos próprios distanciados de $17 \mathrm{~cm}$, por 24 horas, a $5^{\circ} \mathrm{C}$. Depois de resfriadas, as carcaças foram seccionadas ao meio e, em cada lado, efetuados os cortes em sete regiões anatômicas: paleta, perna, lombo, costelas falsas, costelas verdadeiras, baixo e pescoço
(Colomer-Rocher \& Espejo, 1972).

Entre a última vértebra torácica e a primeira lombar, no corte denominado lombo, que compreende as seis vértebras lombares, foram determinadas sobre a superfície do corte transversal do músculo longissimus dorsi, a área de olho de lombo e as seguintes medidas com o uso de um paquímetro: medida A ou largura máxima do longissimus dorsi, perpendicular ao eixo ou medida B; medida B ou profundidade máxima do músculo; medida $\mathrm{C}$ ou espessura mínima de gordura sobre a secção transversal do músculo à continuação do eixo B; medida J ou espessura máxima de gordura de cobertura no perfil do lombo (Siqueira \& Fernandes, 2000; Macedo et al., 2000).

A área transversal do músculo longissimus dorsi, ou área de olho de lombo, foi determinada traçando-se o seu contorno em transparência, para posterior mensuração com o programa computacional AutoCAD (AutoCAD release 14.0, versão R14.0.0, copyright 1982 - 1997 by Autodesk, Inc.).

Após as mensurações, os lombos esquerdos e direitos foram embalados em sacos plásticos fechados e congelados para posteriores análises. Os lombos esquerdos foram dissecados para determinação das proporções de carne, ossos e gorduras subcutânea e intermuscular, sendo cada componente pesado separadamente, conforme recomendação de Macedo et al. (2000) e Garcia et al. (2001).

As avaliações da composição química (centesimal) foram feitas no longissimus dorsi dos lombos direitos. O teor de umidade foi avaliado pelo método $950.46 \mathrm{da}$ AOAC (1990) e para proteína foi empregado o método de Kjeldahl-micro, AOAC (1990), item 928.080, para determinação do nitrogênio total. A proteína bruta foi calculada multiplicando-se os teores de nitrogênio total pelo fator 6,25; o extrato etéreo foi determinado segundo AOAC (1990), item 960.39; o resíduo mineral fixo (cinzas), segundo AOAC (1990), item 920.153; o valor calórico (energia), pelocalorímetro PARR 1281; e o pH, por intermédio de pHmetro digital Sentron, com eletrodo de penetração.

As análises objetivas de textura, indicativas de maciez da carne, também foram realizadas no longissimus dorsi dos lombos direitos (Wheller et al., 1995, citados por Villas Bôas, 2001), pelo "Warner Bratzler Shear Force” (5-Speed Drillpress, Model n ${ }^{\circ}$ ZJ4110, Chuck 1/2", Spindle J2513, Motor 1/3 HP).

O delineamento experimental adotado foi o inteiramente casualizado, com três tratamentos e oito

\section{R. Bras. Zootec., v.33, n.4, p.1039-1047, 2004}


repetições, com análises de variância e de regressão realizadas por intermédio do SAS (SAS, 1996). O modelo matemático utilizado incluiu o efeito fixo dos tratamentos (níveis de SGUM) e também da idade ao abate, para que pudesse ser isolado qualquer eventual efeito decorrente da variabilidade de idade entre os animais, à medida que atingissem o peso pré-fixado para o abate.

\section{Resultados e Discussão}

Os valores médios encontrados para as medidas objetivas (A, B, C, J), força de cisalhamento e área de olho de lombo estão listados na Tabela 1. Não houve efeito significativo $(\mathrm{P}>0,05)$ dos níveis de substituição de GSM pela SGUM para as medidas tomadas no longissimus dorsi, exceto para a área de olho de lombo (AOL).

Os valores médios obtidos para as medidas: A, largura máxima (54,9 mm); B, profundidade máxima (26,82 mm); C, espessura mínima de gordura (1,57 mm); e J, espessura máxima de gordura sobre o lombo (2,57 mm), apresentaram-se um pouco inferiores aos resultados obtidos por Neres et al. (2000), com animais da mesma raça criados em creep feeding, alimentados com diferentes níveis de feno de alfafa na dieta e abatidos com idade média de 82 dias
$(\mathrm{A}=57,87 ; \mathrm{B}=29,8 ; \mathrm{C}=3,13 ; \mathrm{J}=4,45 \mathrm{~mm})$. Provavelmente, a maior idade ao abate dos animais nesse experimento deve ter favorecido essa maior deposição de gordura.

Fernandes (1994) obteve resultados similares aos do presente experimento, porém ligeiramente menores para as medidas de largura e profundidade máximas do longissimus dorsi e pouco maiores para as espessuras mínima e máxima de gordura de 53,6; 24,9; 1,57 e 3,24 mm, respectivamente. Esse autor trabalhou com cordeiros Bergamácia x Ile de France criados em pasto com suas mães e desmamados com idade média de 60 dias e peso vivo (PV) de 10-12 kg. Após a desmama, esses cordeiros foram confinados até atingirem 30-32 kg de PV. Em outro experimento, Garcia (2002), utilizando peso ao abate de $31 \mathrm{~kg}$, obteve os valores: $\mathrm{A}=53,4 ; \mathrm{B}=29,9 ; \mathrm{C}=1,83$ e $\mathrm{J}=3,50 \mathrm{~mm}$, ao testar diferentes níveis de energia em rações oferecidas para cordeiros Suffolk em creep feeding. Os maiores pesos ao abate dos animais nesses experimentos, provavelmente, devem ter favorecido, comparativamente, esse maior acúmulo de gordura subcutânea, sem, contudo, aumentar as medidas A e B, indicativas de proporção muscular na carcaça.

No presente experimento, adotou-se o peso vivo final de $28 \mathrm{~kg}$, usado por Neres et al. (2001) e considerado mais adequado para o atual mercado

\begin{tabular}{|c|c|c|c|c|c|c|}
\hline \multirow{2}{*}{$\begin{array}{l}\text { Table } 1 \text { - } \\
\\
\text { Variáveis } \\
\text { Variable }\end{array}$} & \multirow{2}{*}{$\begin{array}{c}\text { ation (CV } \\
\text { high mo } \\
\text { SGUM } \\
0 \% \\
\text { HMCS }\end{array}$} & \multirow{2}{*}{$\begin{array}{c}\text { of objec } \\
\text { sture corr } \\
50 \% \\
\text { SGUM } \\
50 \% \\
\text { HMCS }\end{array}$} & \multirow{2}{*}{$\begin{array}{c}\text { ive meas } \\
\text { silage }(H \\
100 \% \\
\text { SGUM } \\
100 \% \\
\text { HMCS }\end{array}$} & \multirow{2}{*}{$\begin{array}{l}\text { es }(A, B, \\
C S) \text { in } C \\
\text { Média } \\
\text { Mean }\end{array}$} & \multirow[b]{2}{*}{ CV\% } & \multirow[b]{2}{*}{$\begin{array}{l}\text { Efeito } \\
\text { Effect }\end{array}$} \\
\hline & & & & & & \\
\hline $\begin{array}{l}\text { Largura máxima - A }(\mathrm{mm}) \\
\text { Maximum width - } A(\mathrm{~mm})\end{array}$ & 54,93 & 54,26 & 55,52 & 54,90 & 5,85 & NS \\
\hline $\begin{array}{l}\text { Profundidade máxima-B }(\mathrm{mm}) \\
\text { Maximum depth - B (mm) }\end{array}$ & 26,14 & 27,90 & 26,42 & 26,82 & 8,87 & NS \\
\hline $\begin{array}{l}\text { Espessura mínima de gordura - C (mm) } \\
\text { Minimal fat thickness - } C(\mathrm{~mm})\end{array}$ & 1,46 & 1,79 & 1,45 & 1,57 & 30,88 & NS \\
\hline $\begin{array}{l}\text { Espessura máxima de gordura - J (mm) } \\
\text { Maximum fat thickness - } J(\mathrm{~mm})\end{array}$ & 2,36 & 3,13 & 2,21 & 2,57 & 35,16 & NS \\
\hline $\begin{array}{l}\text { Área de olho de lombo }\left(\mathrm{cm}^{2}\right) \\
\text { Loin eye área }\left(\mathrm{cm}^{2}\right)\end{array}$ & 11,73 & 13,12 & 12,98 & 12,61 & 7,10 & 2 \\
\hline $\begin{array}{l}\text { Força de cisalhamento (kgf) } \\
\text { Shear force (kgf) }\end{array}$ & 2,68 & 2,96 & 2,89 & 2,84 & 22,38 & NS \\
\hline $\begin{array}{l}\text { NS }=\text { Não significativo }(P>0,05) . \\
2=\text { Efeito quadrático }(P<0,05) . \\
\text { NS } \\
=\text { Not significant }(P>05) . \\
=\text { Quadratic effect }(P<.05) .\end{array}$ & & & & & & \\
\hline
\end{tabular}

R. Bras. Zootec., v.33, n.4, p.1039-1047, 2004 
brasileiro (Silva \& Pires, 2000; Bueno et al., 2000; Siqueira et al., 2001a).

A cobertura de gordura é importante indicador de qualidade, porque, além de aparentemente influir na solubilidade do colágeno da carne, afeta diretamente a velocidade de resfriamento da carcaça, comportando-se como isolante térmico e interferindo no processo de conversão do músculo em carne (Felício, 1996).

Houve efeito de tratamento $(\mathrm{P}<0,05)$ para a AOL, obedecendo ao modelo quadrático $\hat{\mathrm{Y}}=11,727625+$ $0,043125 x-0,000306 x^{2} ; R^{2}=37,9 \%$ (Figura 1). Os animais suplementados com rações contendo 0,50 ou $100 \%$ de inclusão de SGUM apresentaram, respectivamente, 11,$73 ; 13,12$ e $12,98 \mathrm{~cm}^{2}$ de AOL, o que indicaria, a princípio, maior deposição de tecido muscular nos animais que receberam SGUM. No conjunto total dos animais do presente experimento, a AOL média foi de $12,61 \mathrm{~cm}^{2}$.

Reis et al. (2001) confinaram animais cruzados Bergamácia x Corriedale desmamados com 50 dias de idade e abatidos, em média, com 33 kg de PV, não encontrando efeito significativo $(\mathrm{P}>0,05)$ dos tratamentos com grãos de milho conservados e/ou processados sob as formas de GMS, SGUM e silagem de grãos de milho hidratados sobre AOL. Esses autores obtiveram o valor médio de $12,69 \mathrm{~cm}^{2}$ para os trata-

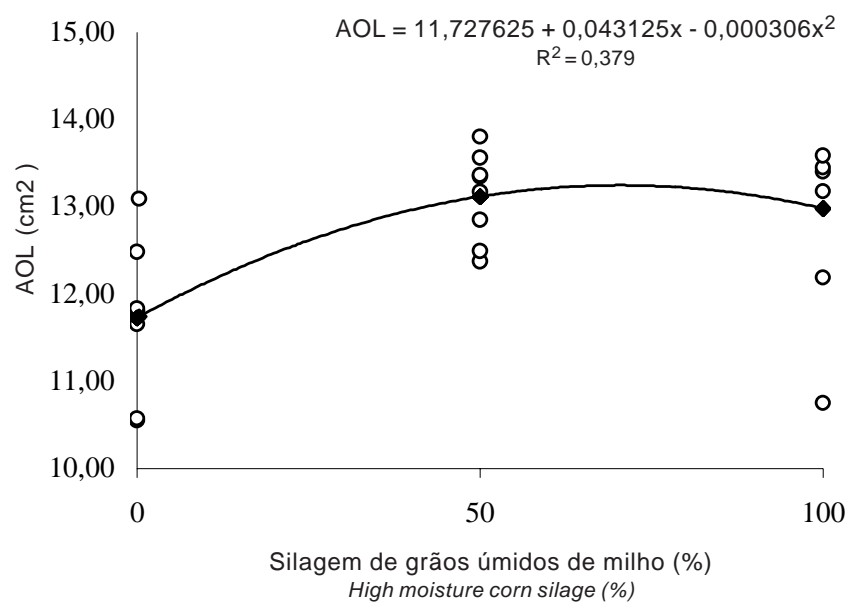

Figura 1 - Área de olho de lombo (AOL) de cordeiros $\left(\mathrm{cm}^{2}\right)$, alimentados em creep feeding, em função da inclusão (\%) de silagem de grãos úmidos de milho na ração. Valores observados (o) e estimados (•).

Figure 1 - Loin eye area $(A O L)$ of lambs $\left(\mathrm{cm}^{2}\right)$, according to inclusion of high moisture corn silage fed to lambs in creep feeding (\%). Observed values (0) and estimated values ( $\bullet$ ). mentos com os mesmos alimentos e proporções testados nesta pesquisa e obtiveram valores compatíveis com carcaças de alta qualidade.

Garcia (2002), testando diferentes níveis de energia na dieta de cordeiros Suffolk em creep feeding também não encontrou diferenças na AOL entre os tratamentos, ao abater os animais com $31,0 \mathrm{~kg}$ de PV. Esse autor obteve a média de $12,62 \mathrm{~cm}^{2}$, similar à encontrada no presente experimento. Áreas menores foram obtidas por Cunha et al. (2000), 10,30 $\mathrm{cm}^{2}$ para cordeiros mestiços Suffolk abatidos aos $33,7 \mathrm{~kg}$ de PV, e Silva \& Pires (2000), 10,97 $\mathrm{cm}^{2}$ para essa mesma variável em cordeiros mestiços Texel x Ideal, abatidos aos $28 \mathrm{~kg}$ de PV.

Não houve efeito de tratamento sobre a variável força de cisalhamento - indicativo da maciez da carne -, que apresentou média de 2,84 kgf (Tabela 1). Russo et al. (1999) não obtiveram diferença $(\mathrm{P}>0,05)$ quanto à maciez da carne de cordeiros, utilizando diferentes fontes de energia na dieta. Villas Bôas (2001), trabalhando com cordeiros Hampshire Down em creep feeding recebendo dietas à base de GMS e farelo de soja, encontraram, em média, 1,57 kgf, para animais abatidos com mesmo peso e idade média de 69 dias.

Sañudo (2002) relatou que valores crescentes ou decrescentes para força de cisalhamento podem ser encontrados em animais jovens, de acordo com a idade de abate, talvez em função de interações entre diferentes taxas de deposição de colágeno e gordura no músculo do animal. Esse mesmo autor, avaliando características indicativas de qualidade da carne de cordeiros jovens, comparou carcaças com diferentes pesos e obteve força de cisalhamento de 3,42; 4,77 e 3,44 kgf nas carcaças com 8,07; 10,22 e 13,4 kg, respectivamente, de cordeiros da raça Aragonesa. Provavelmente pelo fato de, no presente experimento, as idades ao abate terem sido muito próximas entre os tratamentos, esses efeitos não foram observados, mas a força de cisalhamento foi menor que a descrita pelo referido autor, embora o mesmo tenha trabalhado com carcaças predominantemente de menores pesos.

Comparativamente à carne bovina de animais jovens, os valores obtidos neste experimento podem ser considerados muito bons, uma vez que Silveira et al. (1999) obtiveram 5,4 kgf para carnes não maturadas de novilhos superprecoces - indicativo de elevada maciez para a carne desses animais.

A dissecção dos lombos dos cordeiros mostrou que a composição tecidual dos mesmos, inclusiveo percentual de músculos, não foi afetada $(\mathrm{P}>0,05)$ pelos tratamentos

R. Bras. Zootec., v.33, n.4, p.1039-1047, 2004 
(Tabela 2). Esses resultados aparentemente contraditórios com os obtidos na avaliação da AOL, que indicariam maior deposição muscular nos animais tratados com SGUM, reforçam a afirmação de Muller (1980), citado por Oliveira et al. (2002), de que a AOL não deve ser considerada isoladamente de outros parâmetros, uma vez que a mesma por si só não representa alta correlação com a proporção de músculo na carcaça.

Os pesos médios encontrados foram: lombo (683,84 g), músculos (396,60 g), gordura intermuscular (38,37 g), gordura subcutânea $(38,05$ g), gordura perirenal (21,50 g), tecido conjuntivo $(27,96 \mathrm{~g})$ e ossos $(133,86)$. Considerando o somatório das gorduras, obtém-se o total de 97,92 g.

Siqueira et al. (2001a) e Siqueira et al. (2001b) trabalharam com cordeiros mestiços Ile de France $x$ Corriedale, inteiros, desmamados aos 12 kg (60 dias de idade) e abatidos aos 28 kg de peso vivo (PV) após 67 dias de confinamento e obtiveram pesos semelhantes para os mesmos tecidos componentes do lombo: músculos (382,00 g), gordura (102,25 g) e ossos (112,50 g). Essa semelhança de valores sugere que a suplementação alimentar com concentrados tenha papel preponderante na composição tecidual da carcaça de cordeiros, independentemente do grupo racial utilizado. Contudo, no presente experimento, os animais foram abatidos com 64,88 (0\% SGUM), 61,13 (50\% SGUM) e 61,43 (100\% SGUM) dias de idade, ou seja, cerca da metade do tempo gasto no trabalho acima citado.

Em dissecção de lombos de cordeiros Corriedale e mestiços Ile de France x Corriedale, Fernandes (1994) obteve, respectivamente, os seguintes valores percentuais: músculos (52 e 59,8\%), ossos (15,6 e $13,8 \%)$, gordura subcutânea (12,7 e 9,5\%) e gordura intermuscular (5,8 e 6,1\%). No presente experimento, os valores percentuais equivalentes obtidos foram: músculos (58,0\%), ossos (19,6\%), gordura subcutânea $(5,6 \%)$ e intermuscular (5,6\%). A dissecção dos lombos mostrou que os cordeiros apresentaram composições satisfatórias de músculos (carne) e gordura ao abate aos $28 \mathrm{~kg}$ de PV.

Costa et al. (1999), em revisão sobre os locais de deposição de gordura nas carcaças de bovinos e ovinos alimentados com diferentes fontes de amido com maior ou menor digestão ruminal, mostraram que fontes de amido com maior digestão ruminal, como no caso da SGUM, tendem a aumentar a deposição de gordura nos tecidos musculares.

A análise química da carne dos lombos revelou que não houve efeito significativo dos tratamentos $(\mathrm{P}>0,05)$ sobre os teores de umidade, cinzas, proteína bruta, $\mathrm{pH}$ e

Tabela 2 - Médias e coeficientes de variação (CV\%) da composição tecidual do lombo de cordeiros alimentados com silagem de grãos úmidos de milho (SGUM) em creep feeding

Table 2 - Means and coefficients of variation (CV\%) of loin tissue components of lambs fed high moisture corn silage (HMCS) in creep feeding

\begin{tabular}{|c|c|c|c|c|c|c|}
\hline $\begin{array}{l}\text { Variáveis } \\
\text { Variable }\end{array}$ & $\begin{array}{c}0 \% \\
\text { SGUM } \\
0 \% \\
H M C S\end{array}$ & $\begin{array}{c}50 \% \\
\text { SGUM } \\
50 \% \\
H M C S\end{array}$ & $\begin{array}{c}100 \% \\
\text { SGUM } \\
100 \% \\
\text { HMCS }\end{array}$ & $\begin{array}{l}\text { Média } \\
\text { Mean }\end{array}$ & CV\% & $\begin{array}{l}\text { Efeito } \\
\text { Effect }\end{array}$ \\
\hline Peso do lombo (g) & 665,08 & 690,78 & 695,67 & 683,84 & 10,95 & NS \\
\hline $\begin{array}{l}\text { Loin weight (g) } \\
\text { Músculos (g) } \\
\text { Muscle (g) }\end{array}$ & 391,55 & 392,15 & 406,11 & 396,60 & 7,22 & NS \\
\hline $\begin{array}{l}\text { Gordura intermuscular (g) } \\
\text { Intermuscular fat (g) }\end{array}$ & 38,47 & 41,14 & 35,49 & 38,37 & 39,52 & NS \\
\hline $\begin{array}{l}\text { Gordura subcutânea (g) } \\
\text { Subcutaneous fat (g) }\end{array}$ & 35,71 & 43,44 & 35,00 & 38,05 & 41,94 & NS \\
\hline $\begin{array}{l}\text { Gordura perirenal (g) } \\
\text { Perirenal fat (g) }\end{array}$ & 21,58 & 22,42 & 20,51 & 21,50 & 37,69 & NS \\
\hline $\begin{array}{l}\text { Tecido conjuntivo (g) } \\
\text { Conjunctive tissue (g) }\end{array}$ & 22,56 & 28,41 & 32,90 & 27,96 & 35,65 & NS \\
\hline $\begin{array}{l}\text { Ossos }(\mathrm{g}) \\
\text { Bone }(\mathrm{g})\end{array}$ & 120,17 & 132,54 & 148,86 & 133,86 & 28,94 & NS \\
\hline
\end{tabular}

NS = Não significativo $(P>0,05)$

$N S=$ Not significant $(P>05)$

R. Bras. Zootec., v.33, n.4, p.1039-1047, 2004 
energia (Tabela 3). A idade ao abate também não influenciou $(\mathrm{P}>0,05)$ esses mesmos parâmetros.

Rowe et al. (1999) relataram a seguinte composição química para a carne de cordeiros terminados em pasto e confinados, respectivamente: umidade (71,0 e 66,5\%), cinzas (0,9 e 0,9\%), proteína (19,3 e $19,4 \%)$ e gordura $(6,8$ e $10,8 \%)$. Nota-se, com base nos resultados deste experimento, que o principal constituinte que sofreu variações em função do sistema de alimentação foi a gordura $(\mathrm{P}<0,01)$, indicando que dietas ricas em alimentos concentrados tendem a gerar carcaças mais gordas.

No presente trabalho, os teores totais de gordura intermuscular, subcutânea e perirenal não apresentaram efeito de tratamento nas dissecções dos lombos, talvez pelo fato de que todos os animais tenham sido criados sob o mesmo sistema de suplementação alimentar em creep feeding.

No entanto, a substituição do milho moído pela SGUM afetou $(\mathrm{P}<0,01)$ o teor de extrato etéreo, segundoa equação $\hat{Y}=1,773547+0,006162 x ; R^{2}=32,5 \%$. O percentual de extrato etéreo no longissimus dorsi, que é bom indicativo do percentual de gordura intramuscular da carcaça, aumentou linearmente, à medida que se incluiu SGUM nas rações (Figura 2).

De acordo com Costa et al. (2002), o extrato etéreo corresponde aos lipídeos depositados entre as células e no interior das mesmas e aumentos da porcentagem de extrato etéreo tendem a estar associados a incrementos de palatabilidade e suculência da carne sem, contudo, apresentarem associações com aumento de maciez. Esses autores, avaliando carcaças de bovinos jovens confinados, observaram alta correlação do extrato etéreo no músculo longissimus dorsi com o teor de gordura intramuscular (marmoreio) e o de gordura total na carcaça, e baixa correlação com o teor de gordura subcutânea.

Neste experimento, os resultados obtidos não corroboram totalmente essas evidências, talvez em função de características peculiares à espécie ovina. Deve-se considerar, também, que a avaliação do teor de gordura foi feita apenas no lombo, não havendo, portanto, uma avaliação geral da carcaça ou de outros parâmetros correlatos avaliados pelos referidos autores.

Outros trabalhos também demonstraram que cordeiros alimentados com concentrados apresentaram maior porcentagem de extrato etéreo na carcaça e, embora o teor de gordura talvez não esteja diretamente relacionado ao sabor da carne, certos componentes dos depósitos de gordura intramuscular contribuem para que o sabor seja alterado (Summer et al., 1978; Lopez-Francos, 1991; citados por Neto, 1997).

Tabela 3 - Médias e coeficientes de variação (CV\%) das composições químicas do longissimus dorsi de cordeiros alimentados com silagem de grãos úmidos de milho (SGUM) em creep feeding

Table 3 - Means and coefficients of variation (CV\%) of chemical composition of longissimus dorsi of lambs fed high moisture corn silage (HMCS) in creep feeding

\begin{tabular}{|c|c|c|c|c|c|c|}
\hline $\begin{array}{l}\text { Variáveis } \\
\text { Variable }\end{array}$ & $\begin{array}{c}0 \% \\
\text { SGUM } \\
0 \% \\
\text { HMCS } \\
\end{array}$ & $\begin{array}{c}50 \% \\
\text { SGUM } \\
50 \% \\
\text { HMCS }\end{array}$ & $\begin{array}{c}100 \% \\
\text { SGUM } \\
100 \% \\
\text { HMCS }\end{array}$ & $\begin{array}{l}\text { Valores médios } \\
\text { Mean values }\end{array}$ & CV (\%) & $\begin{array}{l}\text { Efeito } \\
\text { Effect }\end{array}$ \\
\hline $\begin{array}{l}\text { Umidade (\%) } \\
\text { Humidity (\%) }\end{array}$ & 74,74 & 74,90 & 74,61 & 74,75 & 1,02 & NS \\
\hline $\begin{array}{l}\text { Cinzas (\%) } \\
\text { Ash (\%) }\end{array}$ & 1,18 & 1,27 & 1,20 & 1,22 & 6,88 & NS \\
\hline $\begin{array}{l}\text { Extrato etéreo (\%) } \\
\text { Ether extract (\%) }\end{array}$ & 1,78 & 2,08 & 2,39 & 2,08 & 17,92 & 1 \\
\hline $\begin{array}{l}\text { Proteína bruta (\%) } \\
\text { Crude protein (\%) }\end{array}$ & 21,77 & 21,48 & 21,15 & 21,47 & 3,77 & NS \\
\hline $\begin{array}{l}\mathrm{pH} \\
\mathrm{pH}\end{array}$ & 5,69 & 5,63 & 5,62 & 5,65 & 2,45 & NS \\
\hline $\begin{array}{l}\text { Energia }(\mathrm{kcal} / 100 \mathrm{~g}) \\
\text { Energy }(\mathrm{kcal} / 100 \mathrm{~g})\end{array}$ & 144,09 & 151,13 & 145,09 & 146,77 & 5,08 & NS \\
\hline
\end{tabular}

NS = Não significativo $(P>0,05)$.

1 = Efeito linear $(P<0,01)$.

NS $=$ Not significant $(P>.05)$.

$1=$ Linear effect $(P<.01)$.

R. Bras. Zootec., v.33, n.4, p.1039-1047, 2004 


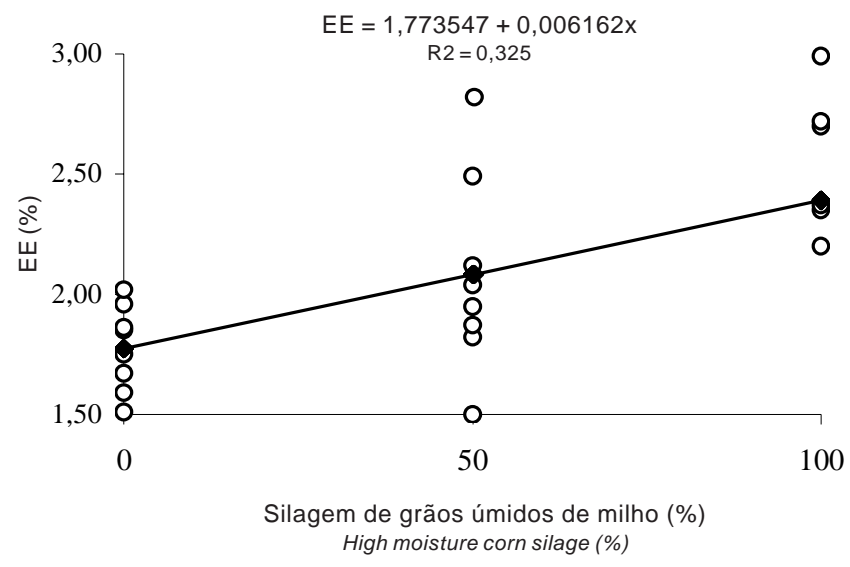

Figura 2 - Extrato etéreo (EE) no longissimus dorsi (\%) de cordeiros alimentados em creep feeding, em função da inclusão (\%) de silagem de grãos úmidos de milho na ração. Valores observados (o) e estimados ( $\bullet$ ).

Figure 2 - Ether extract (EE) of longissimus dorsi (\%) of lambs, according to inclusion of high moisture corn silage fed to lambs in creep feeding (\%). Observed values (o) and estimated values ( $\bullet$ ).

Esse fato ressalta que a gordura intramuscular pode ter contribuição preponderante para a qualidade final da carne. Outros trabalhos avaliando características sensoriais da carne de cordeiros criados neste sistema devem ser realizados para melhor compreensão deste comportamento.

\section{Conclusões}

A silagem de grãos úmidos de milho pode substituir totalmente os grãos secos de milho em rações para cordeiros criados em creep feeding e abatidos com $28 \mathrm{~kg}$ de peso vivo, por elevar o teor de gordura, sem alterar as medidas objetivas, cobertura de gordura e maciez tomadas no músculo longissimus dorsi.

\section{Literatura Citada}

ASSOCIATION OF OFFICIAL ANALYTICAL CHEMISTS AOAC. Official methods of analysis. 15.ed. Virginia, Washington: Arlington, 1990. 1298p.

BUENO, M.S.; CUNHA, E.A.; SANTOS, L.E. et al. Características de carcaça de cordeiros Suffolk abatidos em diferentes idades. Revista Brasileira de Zootecnia, v.29, n.6, p.1803-1810, 2000.

COLOMER-ROCHER, F.; ESPEJO, M.D. Determinación del peso óptimo de sacrificio de los corderos procedentes del cruzamiento Manchego x Raza Aragonesa en función del sexo. Revista ITEA, n.4, p.219-235, 1972.

COSTA, C.; ARRIGONI, M.B.; SILVEIRA, A.C. Silagem de grãos úmidos. In: SIMPÓSIO SOBRE NUTRIÇÃO DE BOVINOS, 7., 1999, Piracicaba. Anais... Piracicaba: Fundação de Estudos Agrários Luiz de Queiroz, 1999. p.69-88.

COSTA, E.C.; RESTLE, J.; BRONDANI, I.L. et al. Composição física da carcaça, qualidade da carne e conteúdo de colesterol no músculo Longissimus dorsi de novilhos Red Angus superprecoces, terminados em confinamento e abatidos com diferentes pesos. Revista Brasileira de Zootecnia, v.31, n.1, p.417-428, 2002.

CUNHA, E.A.; SANTOS, L.F.; BUENO, M.S. et al. Utilização de carneiros de raças de corte para obtenção de cordeiros precoces para abate em plantéis produtores de lã. Revista Brasileira de Zootecnia, v.29, n.1, p.243-252, 2000.

FELÍCIO, P.E. Fatores ante e post mortem que influenciam na qualidade da carne bovina. In: SIMPÓSIO SOBRE PECUÁRIA DE CORTE, 4., 1996, Piracicaba. Anais... Piracicaba: Fundação de Estudos Agrários Luiz de Queiroz, 1997. p.79-97.

FERNANDES, S. Peso vivo ao abate e características de carcaça de cordeiros da raça Corriedale e mestiços Ile de France $x$ Corriedale recriados em confinamento. Botucatu: Universidade Estadual Paulista, 1994. 82p. Dissertação (Mestrado em Zootecnia) - Universidade Estadual Paulista, 1994.

GARCIA, C.A. Níveis de energia na ração de cordeiros em creep feeding. Botucatu: Universidade Estadual Paulista, 2002. 60p. Tese (Doutorado em Zootecnia) - Universidade Estadual Paulista, 2002.

GARCIA, C.A.; NERES, M.A.; MONTEIRO, A.L.G. et al. Análise química e composição tecidual do lombo de cordeiros em creep feeding. In: REUNIÃO ANUAL DA SOCIEDADE BRASILEIRA DE ZOOTECNIA, 38., Piracicaba, 2001. Anais... Piracicaba: Sociedade Brasileira de Zootecnia, 2001, p.1162-1163.

GARCIA, I.F.F.; PEREZ, J.R.O.; TEIXEIRA, J.C. et al. Desempenho de cordeiros Texel x Bergamácia, Texel x Santa Inês e Santa Inês puros, terminados em confinamento, alimentados com casca de café como parte da dieta. Revista Brasileira de Zootecnia, v.29, n.2, p.564-572, 2000.

INSTITUTO BRASILEIRO DE GEOGRAFIA E ESTATÍSTICA - IBGE. Pesquisa da pecuária municipal. 2001. http://www.ibge.gov.br

LUCHIARI FILHO, A.; MOURA, A.C. Influência do peso da carcaça e da espessura de gordura na maciez da carne bovina. Revista Pecuária de Corte, n.75, p.56-58, 1998.

MACEDO, F.A.F.; SIQUEIRA, E.R.; MARTINS, E.N. et al Qualidade de carcaças de cordeiros Corriedale, Bergamácia x Corriedale e Hampshire Down x Corriedale, terminados em pastagem e confinamento. Revista Brasileira de Zootecnia, v.29, n.5, p.1520-1527, 2000.

MATOS, M.S.; MATOS, P.F. Laboratório clínico médicoveterinário. 2.ed. Rio de Janeiro: Atheneu, 1988. 238p.

NERES, M.A.; GARCIA, C.A.; MONTEIRO, A.L.G. et al. Desempenho, peso e rendimentos de carcaças de cordeiros criados em creep feeding. In: REUNIÃO ANUAL DA SOCIEDADE BRASILEIRA DE ZOOTECNIA, 37., 2000, Viçosa. Anais... São Paulo: Sociedade Brasileira de Zootecnia/Gnosis, [2000]. CD-ROM. Nutrição de Ruminantes. NUTR 021.

NERES, M.A.; GARCIA, C.A.; MONTEIRO, A.L.G. et al. Níveis de feno de alfafa e forma física da ração no desempenho de cordeiros em creep feeding. Revista Brasileira de Zootecnia, v.30, n.3, p.941-947, 2001. 
NETO, M.J.L. Caracteres qualitativos da carne de cordeiros da raça Corriedale e mestiços Ile de France x Corriedale, terminados em confinamento. Botucatu: Universidade Estadual Paulista, 1997. 33p. Dissertação (Mestrado em Zootecnia) - Universidade Estadual Paulista, 1997.

OLIVEIRA, M.V.M.; PÉREZ, J.R.O.; ALVES, E.L. et al. Avaliação da composição de cortes comerciais, componentes corporais e órgãos internos de cordeiros confinados e alimentados com dejetos de suínos. Revista Brasileira de Zootecnia, v.31, n.3, p.1459-1468, 2002.

OWENS, F.N.; ZINN, R.A.; KIM, Y.K. Limits to starch digestion in the ruminant small intestine. Journal of Animal Science, v.63, n.5, p.1634-1648, 1986.

REIS, W.; JOBIM, C.C.; MACEDO, F.A.F. et al. Características da carcaça de cordeiros alimentados com dietas contendo grãos de milho conservados em diferentes formas. Revista Brasileira de Zootecnia, v.30, n.4, p.1308-1315, 2001.

ROWE, A.; MACEDO, F.A.F.; VISENTAINER, J.V. et al. Muscle composition and acid profile in drylot or pasture. Meat Science, v.51, p.283-288, 1999.

RUSSO, C.; PREZIUSO, G.; CASAROSA, L. et al. Effect of diet energy source on the chemical - physical characteristics of meat and depot fat of lambs carcasses. Small Ruminants Research, v.33, p.77-85, 1999.

SAÑUDO, C. Factors affecting carcass and meat quality in lambs. In: REUNIÃO ANUAL DA SOCIEDADE BRASILEIRA DE ZOOTECNIA, 39., 2002, Recife. Anais... Recife: Sociedade Brasileira de Zootecnia, 2002. p.434-455.

STATISTICAL ANALYSES SYSTEM - SAS. User's guide: statistics. 5.ed. Cary: 1996. 955p.

SILVA, L.F.; PIRES, C.C. Avaliações quantitativas e predição das proporções de osso, músculo e gordura da carcaça em ovinos. Revista Brasileira de Zootecnia, v.29, n.4, p.1253-1260, 2000.

SILVA SOBRINHO, A.G. Aspectos quantitativos e qualitativos da produção de carne ovina. In: A produção animal na visão dos brasileiros. REUNIÃO ANUAL DA SOCIEDADE BRASILEIRA DE ZOOTECNIA, 38., 2001, Piracicaba. Anais... Piracicaba: Sociedade Brasileira de Zootecnia, 2001. p.425-446.
SILVEIRA, A.C.; ARRIGONI, M.B.; CHARDULO, L.A.L. et al. Sistema de produção de novilhos superprecoces. In: SIMPÓSIO GOIANO SOBRE PRODUÇÃO DE BOVINOS DE CORTE, 1999, Goiânia. Anais... Goiânia: Colégio Brasileiro de Nutrição Animal, 1999. p.105-122.

SIMPLÍCIO, A.A. A caprino-ovinocultura na visão do agronegócio. Revista CFMV, n.24, p.15-18, 2001.

SIQUEIRA, E.R.; FERNANDES, S. Efeito do genótipo sobre as medidas objetivas e subjetivas da carcaça de cordeiros terminados em confinamento. Revista Brasileira de Zootecnia, v.29, n.1, p.306-311, 2000.

SIQUEIRA, E.R.; SIMÕES, C.D.; FERNANDES, S. Efeito do sexo e do peso ao abate sobre a produção de carne de cordeiro. I. Velocidade de crescimento, caracteres quantitativos da carcaça, pH da carne e resultado econômico. Revista Brasileira de Zootecnia, v.30, n.3, p.844-848, 2001a.

SIQUEIRA, E.R.; SIMÕES, C.D.; FERNANDES, S. Efeito do sexo e do peso ao abate sobre a produção de carne de cordeiro. Morfometria da carcaça, pesos dos cortes, composição tecidual e componentes não constituintes da carcaça. Revista Brasileira de Zootecnia, v.30, n.4, p.1299-1307, 2001b.

TANIGUCHI, K.; HUNTINGTON, G.B.; GLENN, B.P. Net nutrient flux by visceral tissues of beef steers given abomasal and ruminal infusions of casein and starch. Journal of Animal Science, v.73, p.236-249, 1995.

VILLAS BÔAS, A.S. Idade à desmama e manejo alimentar na produção de cordeiros superprecoces. Botucatu: Universidade Estadual Paulista, 2001. 55p. Dissertação (Mestrado em Zootecnia) - Universidade Estadual Paulista, 2001.

Recebido em: 11/03/03

Aceito em: 21/10/03 